Focussed on "Crack Paths"

\title{
Cruciform specimens used for determination of the influence of $T$ - stress on fatigue crack growth with overloads on aluminum alloy Al 6061 T651
}

\author{
Sebastian Henkel, Carl H. Wolf, Horst Biermann \\ Institute of Materials Engineering, Technische Universität Bergakademie Freiberg, Gustav-Zeuner-Straße 5, 09599 Freiberg \\ Germany \\ benkel@ww.tu-freiberg.de \\ Carl.Wolf@ww.tu-freiberg.de, https:/ / orcid.org/0000-0003-1406-2598
}

Andreas Burgold, Meinhard Kuna

Institute of Mechanics and Fluid Dynamics, Technische Universität Bergakademie Freiberg, Lampadiusstraße 4, 09599 Freiberg, Germany

andreas.burgold@imfd.tu-freiberg.de

\begin{abstract}
The publication presents a cruciform specimen for the determination of cyclic crack growth data under biaxial loading. The design of the specimen with slotted loading arms allows good decoupling between the two loading directions. For different initial crack geometries, the solutions for the stress intensity factors $K_{\mathrm{I}}$ and $K_{\mathrm{II}}$ as well as the crack-parallel T-stress are calculated by linear elastic finite element analysis (FEA) with the program ABAQUS. For two specimens with the same geometry made of aluminium alloy $6061 \mathrm{~T} 651$, the crack growth behaviour is measured at different Tstresses at a stress ratio of $\mathrm{R}=0.7$ and overloads. It is shown that the crack retardation after an overload with crack-parallel tensile stress is less than without it. The reason for this behaviour is considered to be the reduced plasticity at the crack tip due to the higher triaxiality of the stress state.
\end{abstract}

KEYWORDS. Cruciform specimen; Biaxial testing; Fracture mechanics; T-stress; Overload; Fatigue crack growth.

\section{OPEN ACCESS}

Citation: Henkel, S., Wolf, C. H., Biermann, H., Burgold, A., Kuna, M., Cruciform specimens used for determination of the influence of T-stress on fatigue crack growth with overloads on aluminum alloy $\mathrm{Al} 6061$ T651, Frattura ed Integrità Strutturale, 48 (2019) 135-143.

Received: 30.11 .2018

Accepted: 22.01.2019

Published: 01.04.2019

Copyright: (C) 2019 This is an open access article under the terms of the CC-BY 4.0, which permits unrestricted use, distribution, and reproduction in any medium, provided the original author and source are credited.

\section{INTRODUCTION}

esting of cruciform specimens is useful in a transfer chain from small uniaxial laboratory samples to complex multiaxially loaded components, especially to understand the material behavior under biaxial stress state [1]. Such stress conditions occur, for example, in thin-walled structural components such as the aircraft's outer skin, pressure 
vessels etc. Cruciform specimens are also employed to understand crack growth in blade-integrated disks for gas turbines [2].

For the uniaxial load case, simple specimens are tested often under standardized conditions. Multi-axial testing, on the other hand, uses complex specimens or components that are in many cases subjected to high load gradients and have so far only been standardized in very few cases. Under fatigue testing, not only the loads in several directions can vary, but also the ratio of amplitudes and mean loads, as well as the phase relationship between the several actuators. Depending on the design of the specimen and the test setup, this specimen is subjected to different loads locally. Therefore, the understanding of the crack path and the fatigue crack growth rate in such a specimen often requires a complex numerical stress analysis. Planar biaxial cruciform specimens are known to be more homogenous in stress distribution [3]. However, possible stress gradients and coupling between the loading axes have also to be taken into account in such samples.

a)
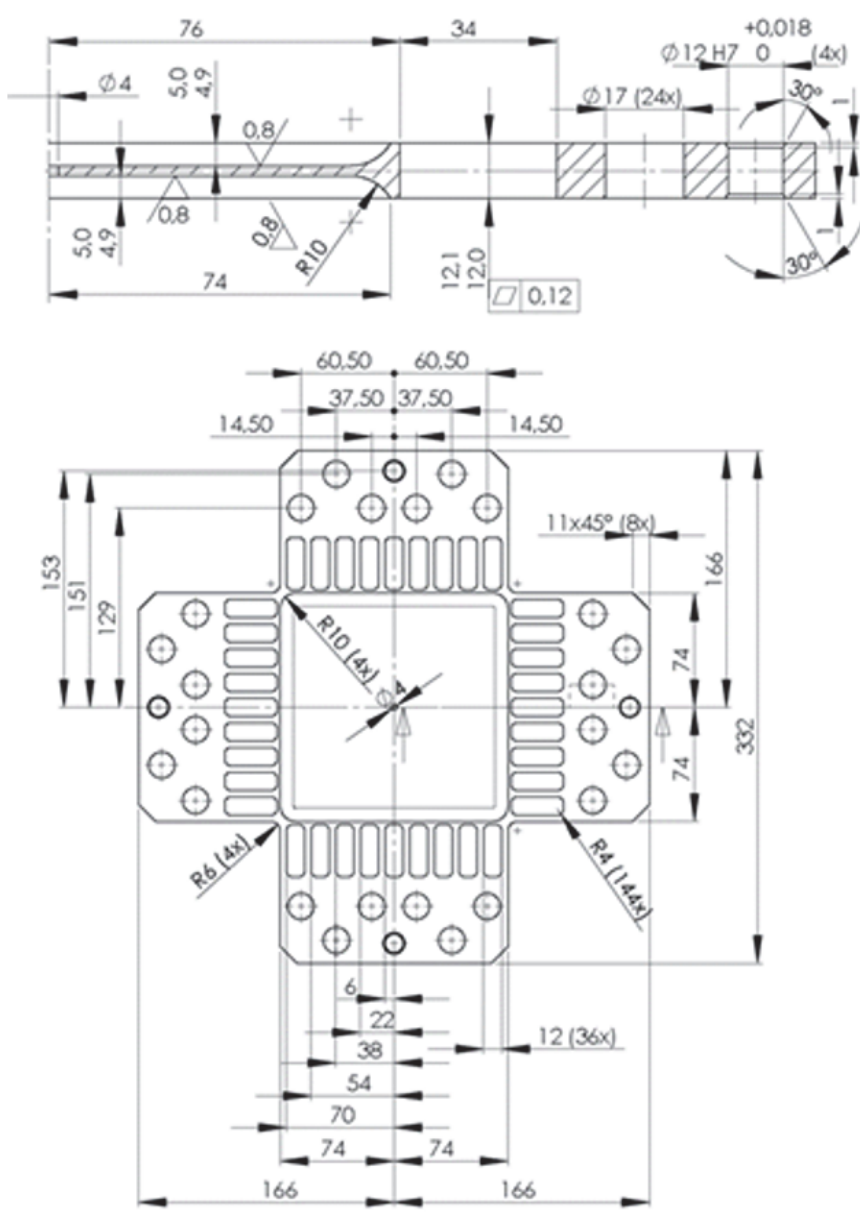

b)

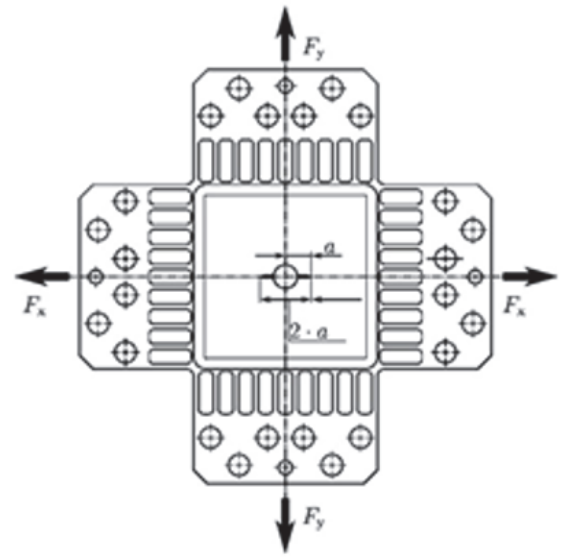

c)

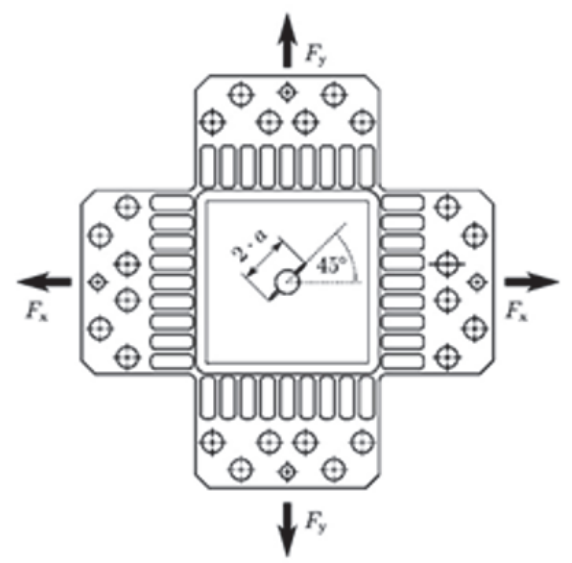

Figure 1: (a) Dimensional drawing $[\mathrm{mm}]$ of the used cruciform specimen with thinned measurement area and slotted arms. (b) Position of the starting notch, center crack, parallel to one loading direction and (c) center crack, orientated $45^{\circ}$ to the loading directions.

\section{MATERIAL AND METHODS}

$\mathrm{F}$ ig. 1a shows the investigated cruciform specimen. The design is according to [4] with slotted loading arms and a thinned inner measurement area. The slits are machined to reduce the stiffness of the loading arms in their perpendicular directions to achieve an uncoupling of the stresses between the two loading directions in the center. To reduce notch effects at the end of the slots, these are rounded off with a radius of $4 \mathrm{~mm}$. Because the slits reduce the load carrying area of the loading arms, the measurement area in the center of the specimen is reduced in thickness. Dalle Donne et al. [5] showed that stress coupling from the specimens' design is sometimes misinterpreted as a material behavior. 
An uncoupled loading in the two loading directions is possible only for a specimen with very long slits. The design in the present contribution is a compromise. The length of the slots is limited by geometrical restrictions of the used $250 \mathrm{kN}$ biaxial test rig Instron 8800 . The specimen is only suitable to a limited extent for testing under compressive forces because the ribs between the slots can buckle. Therefore, slot-free specimens are usually used for symmetrical tensile-compression loading, see for instance Ref. [2].

The concept of stress intensity factor $K$ is widely used in linear elastic fracture mechanics to describe the crack tip load under cyclic loading. In general, cyclic loads are small and the sample behavior is globally elastic. However, the damaging, crackdriving effects and the main counteracting crack closure mechanisms are all based on the plastic deformation at the crack tip. The size of this plastic zone is affected by the triaxiality of stresses in front of the crack tip and depends on specimen thickness and crack-parallel T-stress [6]. Especially for plastically deformable materials, tests with uniaxial samples of different triaxialities lead to different crack growth rates $[7,8]$. In the biaxial stress field, cracks can be exposed not only to mode I load with an opening perpendicular to the crack edges, but also to a sliding displacement parallel to the crack boundaries (mode II). If the direction of the notch or crack is perpendicular to one direction of loading of a cruciform specimen (Fig. 1b), the crack tip is always exposed to a mode I load for isotropic material. The second direction of loading can then be used to change the constraint of the specimen in the direction of crack propagation (T-stress). If the initial crack is centered at $45^{\circ}$ to the loading axes, mixed-mode situations can also be created depending on the load ratio between the loading axes (Fig. 1c). A phase shift of $180^{\circ}$ in time between them theoretically induces a pure mode II loading. Practical tests show mainly a kink or branch in mode I direction [9]. Several incipient cracks outside the center of the specimen can be used, for example, for simulating loads on rivet holes [10]. In the corners of the measuring area, shear stresses occur which can be utilized to generate curved mode I crack paths [11].

The finite element simulations have been carried out with the commercial FE code ABAQUS. The specimens are modeled in two dimensions using the plane stress assumption in a small strain setting. The material (aluminum) is considered as linear elastic and isotropic with a Young's modulus of $72 \mathrm{GPa}$ and a Poisson's ratio of 0.34. Eight-node quadrilateral elements with full integration were used for the mesh.

Since the mechanical problem is linear, the concept of superposition was applied. Finite element calculations were performed for loads $F_{x}$ and $F_{y}$, respectively, and their results are superimposed. The stress state is calculated for the crack-free specimen geometry in order to investigate the force coupling. Stress intensity factors and T-stress were calculated for initial cracks with a length of $5 \mathrm{~mm}$ parallel to one axis and with an inclination of $45^{\circ}$ to the loading axes, compare Figs. $1 \mathrm{~b}$ and c. Based on these results, a force based mixed-mode solution for the stress intensity factors $K_{\mathrm{I}}$ and $K_{\mathrm{II}}$ and the T-stress in the biaxial case is developed:

$$
K_{\mathrm{I}, \mathrm{II}}, T=F_{x} \cdot g_{x \mathrm{I}, \mathrm{II}, \mathrm{T}}(a)+F_{y} \cdot g_{\mathrm{y}, \mathrm{II}, \mathrm{T}}(a)
$$

where $g_{y}$ and $g_{x}$ are the numerically calculated geometry functions which have the unit $\left[\mathrm{MPa} \cdot V_{\mathrm{mm}} / \mathrm{kN}\right]$ for $K_{\mathrm{I}}$ and $K_{\mathrm{II}}$ and $[\mathrm{MPa} / \mathrm{kN}]$ for T-stress. The crack length $a$ is in $[\mathrm{mm}]$ and the forces have the unit $[\mathrm{kN}]$.

Two crack growth experiments were performed on cruciform specimens of aluminum alloy 6061 (EN AW-AlMgSilCu) in the condition T651 (solution annealed, quenched, controlled strained and artificially aged). The material has a chemical composition of $0.76 \% \mathrm{Mg}, 0.56 \% \mathrm{Si}, 0.23 \% \mathrm{Cu}$ and less than $0.7 \%$ Fe. The experiments were carried out on a servohydraulic planar biaxial testing system Instron 8800 with a maximal force of $250 \mathrm{kN}$ for both axes. The initial notch was machined by EDM in $x$-direction (Fig. 1b). The cyclic load was applied by the force $F_{y}$ (perpendicular to the crack). $F_{x}$ (parallel to the crack) was varied as 0 or $40 \mathrm{kN}$ as a (non-cyclic) static load to vary the in-plane constraint conditions. A load of $40 \mathrm{kN}$ corresponds to a stress of $\sigma_{x}=118 \mathrm{MPa}$ in the center of the crack-free specimen. It shifts the T-stress, which is cyclic varying with the load $F_{y}$, to positive values. The load $F_{y}$ was applied under force control with constant load amplitude $(4 \mathrm{kN}$, frequency of $20 \mathrm{~Hz}$ ) for 100,000 cycles, interrupted by a single overload with factor 1.3 in continuously repeating blocks. The cyclic stress intensity factor at the beginning was $\Delta K_{\mathrm{I}}=3.3 \mathrm{MPa} \sqrt{\mathrm{m}}_{\mathrm{m}}$. A stress ratio of $\mathrm{R}=\sigma_{\min } / \sigma_{\text {max }}=0.7$ was used to reduce crack closure effects. Fig. 2 illustrates the forces for loading $F_{x}$ and $F_{y}$ as well as the T-stress during one cycle at the beginning of the test. For the load case $F_{x}=0 \mathrm{kN}$ (uniaxial) it can be found that T-stress is negative (Fig. 2a). With a load $F_{x}=40 \mathrm{kN}$ (Fig. 2b) T-stress is shifted to positive values. The overload sequence is shown in Fig. 2c for both cases. In the case of overload, the signal is triangular, since the overload was introduced with ramps.

The crack lengths were determined using the indirect potential drop method with crack gages (range of $20 \mathrm{~mm}$ ) and a FRACTOMAT of the company Russenberger. In each case, one crack gage per crack end was used. An optical camera system (mvBlueCOUGAR-XD 104 bG) with a resolution of 4.2 megapixel was mounted on the back of the specimens. The observed area was $24 \mathrm{~mm}$ x $24 \mathrm{~mm}$, whereby only one crack per experiment was recorded during the tests. 
a)

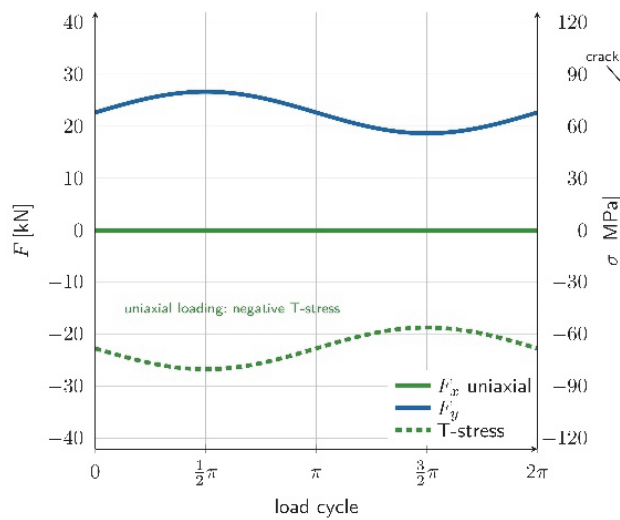

b)

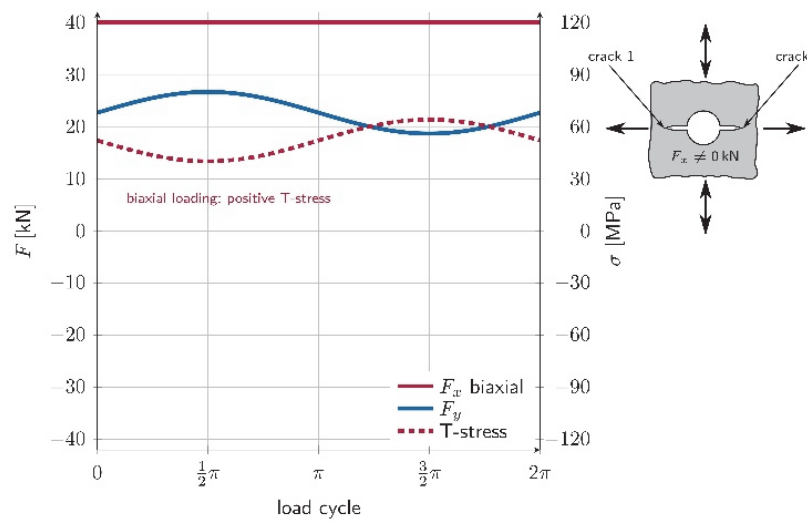

c)

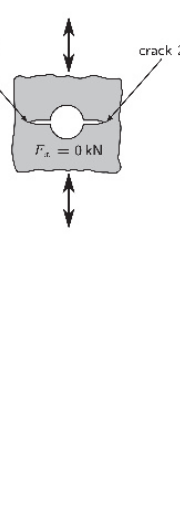

overload sequence

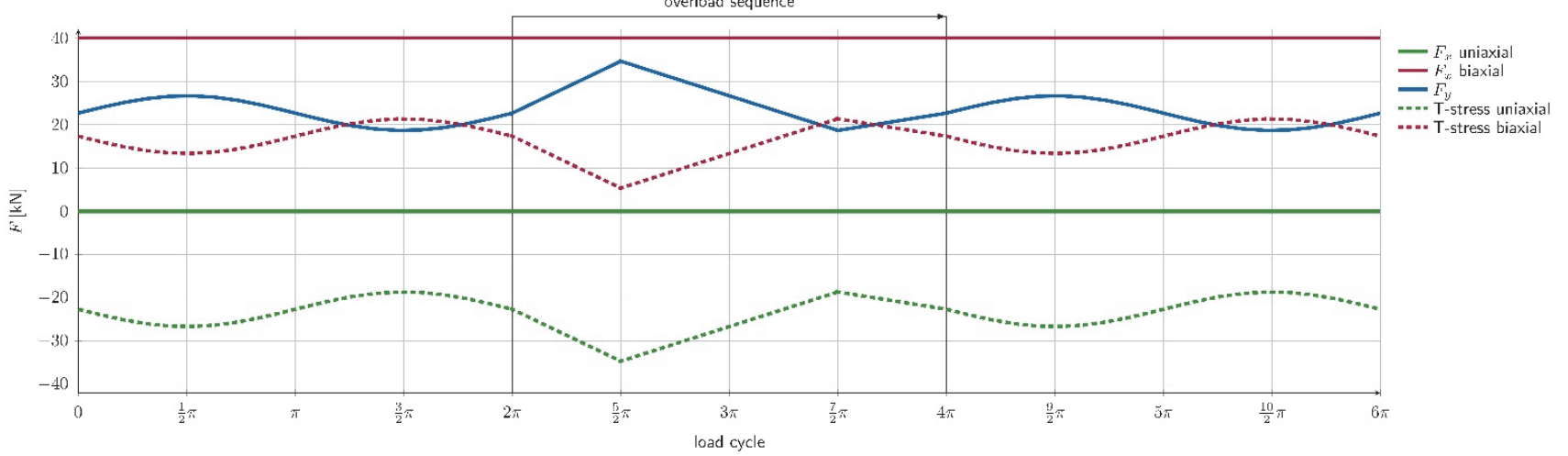

Figure 2: Forces for loading $F_{x}$ and $F_{y}$ and T-stress during one cycle at the beginning of the test. (a) $F_{x}=0 \mathrm{kN}$, negative T-stress, (b) $F_{x}=40 \mathrm{kN}$, positive $T$-stress and (c) overload sequence.

\section{RESULTS AND DISCUSSION}

$\mathrm{T}$

he calculated stress distribution of $\sigma_{y}$ (due to symmetry, $\sigma_{x}=\sigma_{y}$ ) in the crack-free specimen for an equibiaxial load of $1 \mathrm{kN}$ in the two loading axes $F_{x}$ and $F_{y}$ is shown in Fig. $3 \mathrm{a}$. The black lines give us the stresses resulting from the individual loads of $1 \mathrm{kN}$ in $F_{x}$ or $F_{y}$, the colored lines give the superimposed stresses. The stress curve within the measuring range is very homogeneous, especially in the biaxial load case. The coupling of the load axes is shown in Fig. $3 \mathrm{~b}$. It can be seen that a very good decoupling is achieved over large parts of the measuring range and the coupling increases towards the edges.

The solution for the stress intensity factors $K_{\mathrm{I}}$ and $K_{\mathrm{II}}$, as well as the T-stress for the $0^{\circ}$ and $45^{\circ}$ center crack and a load of $1 \mathrm{kN}$ in each axes is given in Tab. 1 . For the $0^{\circ}$ crack the mode II stress intensity factor is $K_{\mathrm{II}}=0$. For the $45^{\circ}$ crack the Tstress and $K_{I}$ have an identical dependency on $F_{x}$ and $F_{y}$, while the solutions of $K_{\text {II }}$ differ in $x$ and $y$ direction only in the sign. Negative values for $K_{I}$ cannot occur at real cracks, since the crack is then closed and no singularity occurs any more. For the calculation according to the superposition principle, however, these negative individual values must also be taken into account.

Continuous solutions for $K_{\mathrm{I}}$ and $\mathrm{T}$ for the $0^{\circ}$ Crack are given by:

$$
\begin{aligned}
K_{\mathrm{I}} & =F_{x} \cdot\left(-2.77206 \cdot 10^{-9} a^{6}+5.64067 \cdot 10^{-7} a^{5}-4.52067 \cdot 10^{-5} a^{4}+1.81991 \cdot 10^{-3} a^{3}-3.81902 \cdot 10^{-2} a^{2}+3.93005 \cdot 10^{-1} a-1.79710\right) \\
& +F_{y} \cdot\left(7.58948 \cdot 10^{-8} a^{5}-1.30521 \cdot 10^{-5} a^{4}+9.90858 \cdot 10^{-4} a^{3}-3.89254 \cdot 10^{-2} a^{2}+1.36616 a+6.03286\right)
\end{aligned}
$$

$\mathrm{T}=F_{\times} \cdot\left(4.92217 \cdot 10^{-8} a^{5}-8.53938 \cdot 10^{-6} a^{4}+5.62448 \cdot 10^{-4} a^{3}-1.68286 \cdot 10^{-2} a^{2}+2.27368 \cdot 10^{-1} a-1.34446\right)$

$+F_{y} \cdot\left(-6.55181 \cdot 10^{-8} a^{5}+1.15588 \cdot 10^{-5} a^{4}-7.76530 \cdot 10^{-4} a^{3}+2.46605 \cdot 10^{-2} a^{2}-3.72137 \cdot 10^{-1} a-0.756542\right)$

For the $45^{\circ}$ oriented crack the solutions for $K_{\mathrm{I}}$ and $K_{\mathrm{II}}$ as well as $\mathrm{T}$ are:

$K_{I}=\left(F_{x}+F_{y}\right) \cdot\left(6.11508 \cdot 10^{-5} a^{3}-7.73378 \cdot 10^{-3} a^{2}+5.44992 \cdot 10^{-1} a+3.25406\right)$ 
$K_{\mathrm{II}}=\left(F_{x-} F_{y}\right) \cdot\left(2.73634 \cdot 10^{-8} a^{5}-6.16073 \cdot 10^{-6} a^{4}+5.64000 \cdot 10^{-4} a^{3}-2.61345 \cdot 10^{-2} a^{2}+8.39372 \cdot 10^{-1} a+1.96109\right)$

$\mathrm{T}=\left(F_{x}+F_{y}\right) \cdot\left(2.67523 \cdot 10^{-9} a^{5}-7.43192 \cdot 10^{-7} a^{4}+7.18089 \cdot 10^{-5} a^{3}-3.02602 \cdot 10^{-3} a^{2}+6.11992 \cdot 10^{-2} a-4.14505 \cdot 10\right)$

a)

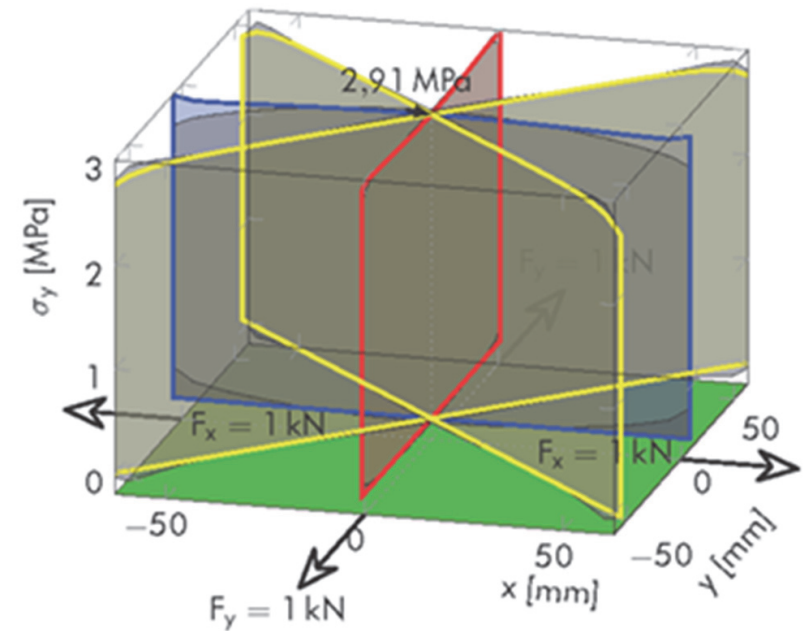

b)

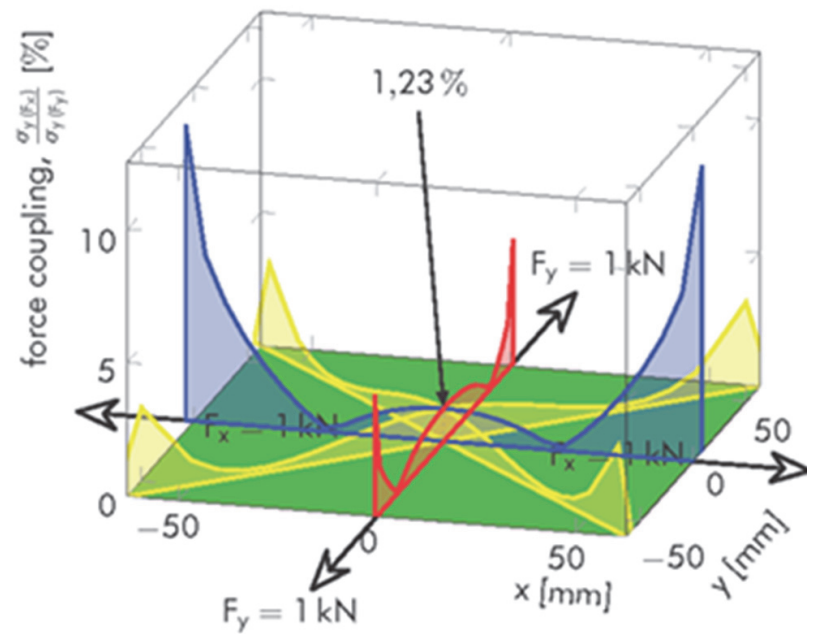

Figure 3: Uncracked specimen without hole, (a) stress distribution for symmetrical (equibiaxial) loading of $1 \mathrm{kN}$, black lines show the stresses resulting from the individual loads, colored lines the superimposed stresses. (b) stress coupling between the loading axes.

a)

\begin{tabular}{r|cc|cc}
\hline \multicolumn{1}{c|}{} & \multicolumn{2}{|c|}{$F_{y}=1 \mathrm{kN}, F_{x}=0 \mathrm{kN}$} & \multicolumn{2}{|c}{$F_{x}=1 \mathrm{kN}, F_{y}=0 \mathrm{kN}$} \\
{$[\mathrm{mm}]$} & $K_{\mathrm{I}}$ & $\mathrm{T}$ & $K_{\mathrm{I}}$ & $\mathrm{T}$ \\
5 & 11.99 & -2.050 & -0.61 & 1.686 \\
10 & 16.67 & -2.675 & -0.28 & 2.616 \\
20 & 23.86 & -2.896 & -0.25 & 2.878 \\
30 & 30.02 & -2.944 & -0.19 & 2.908 \\
40 & 36.16 & -2.973 & -0.02 & 2.888 \\
50 & 43.03 & -3.023 & 0.28 & 2.837 \\
60 & 51.76 & -3.180 & 0.81 & 2.729 \\
& & & & \\
& & & & \\
& & &
\end{tabular}

b)

\begin{tabular}{|c|c|c|c|}
\hline \multirow{3}{*}{$\begin{array}{c}a \\
{[\mathrm{~mm}]}\end{array}$} & \multicolumn{3}{|c|}{$F_{y}=1 \mathrm{kN}, F_{x}=0 \mathrm{kN}$} \\
\hline & $K_{\mathrm{I}}$ & $K_{\mathrm{II}}$ & $\mathrm{T}$ \\
\hline & {$[\mathrm{MPa} \sqrt{\mathrm{mm}}]$} & {$[\mathrm{MPa} \sqrt{\mathrm{mm}}]$} & {$[\mathrm{MPa}]$} \\
\hline 5 & 5.69 & -5.54 & -0.185 \\
\hline 10 & 8.15 & -8.32 & -0.018 \\
\hline 20 & 11.56 & -11.84 & 0.043 \\
\hline 30 & 14.21 & -14.54 & 0.102 \\
\hline 40 & 16.56 & -16.89 & 0.172 \\
\hline 50 & 18.87 & -19.13 & 0.246 \\
\hline 60 & 21.37 & -21.46 & 0.309 \\
\hline 70 & 24.42 & -24.21 & 0.335 \\
\hline 80 & 28.68 & -27.93 & 0.201 \\
\hline
\end{tabular}

Table 1: Results of the FEA for the stress intensity factors $K_{\mathrm{I}}$ and $K_{\mathrm{II}}$ as well as the T-stress for the two crack configurations of a) $0^{\circ}$ and b) $45^{\circ}$ to the loading axis $F_{x}$. For the $45^{\circ} \mathrm{crack}$ and the case $F_{x}=1 \mathrm{kN}$ and $F_{y}=0 \mathrm{kN}, K_{\mathrm{I}}$ and $\mathrm{T}$ are equal to the values in the table, but $K_{\mathrm{II}}$ changes just the sign.

The crack length versus cycles is plotted for the two specimens in Fig. 4. The corresponding crack growth rates are given as function of the stress intensity factor range in Fig. 5. For the specimen with a constant load $F_{x}=40 \mathrm{kN}$, only one crack is plotted because crack growth occurred symmetrically on both cracks tips. After each overload, a small crack acceleration is observed followed by crack retardation. The initial crack growth rate is then reached again. For the case without a load parallel to the crack propagation direction $\left(F_{x}=0 \mathrm{kN}\right)$ the effect of crack retardation is more pronounced. After the overload, the initial crack growth rate is not reached within 100,000 cycles until the next overload is applied. 


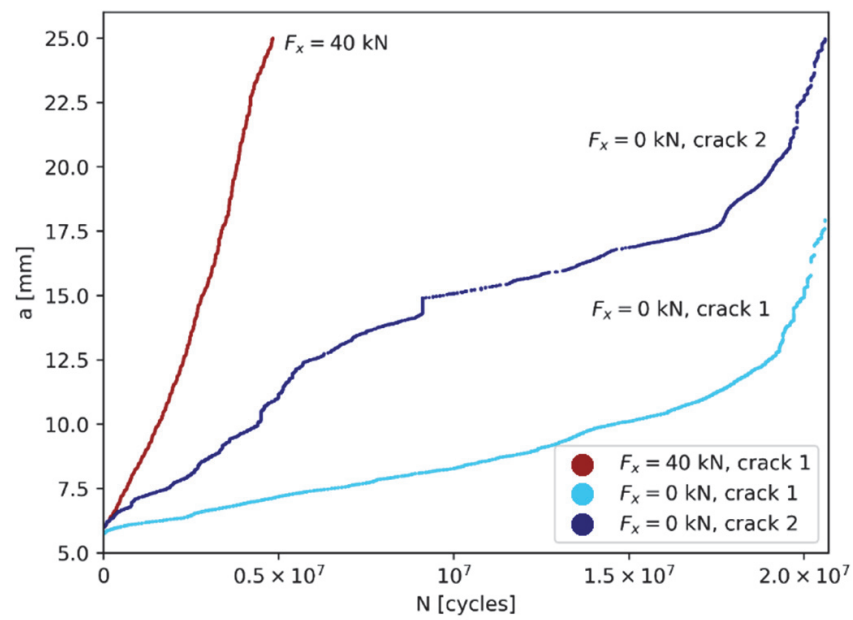

Figure 4: Crack length versus number of cycles for two cruciform specimens with same initial crack setup and fatigue loading in Fy and different forces parallel to the crack propagation direction $F_{x}$. Constant amplitude loading with a single overload every 100.000 cycles.

a)

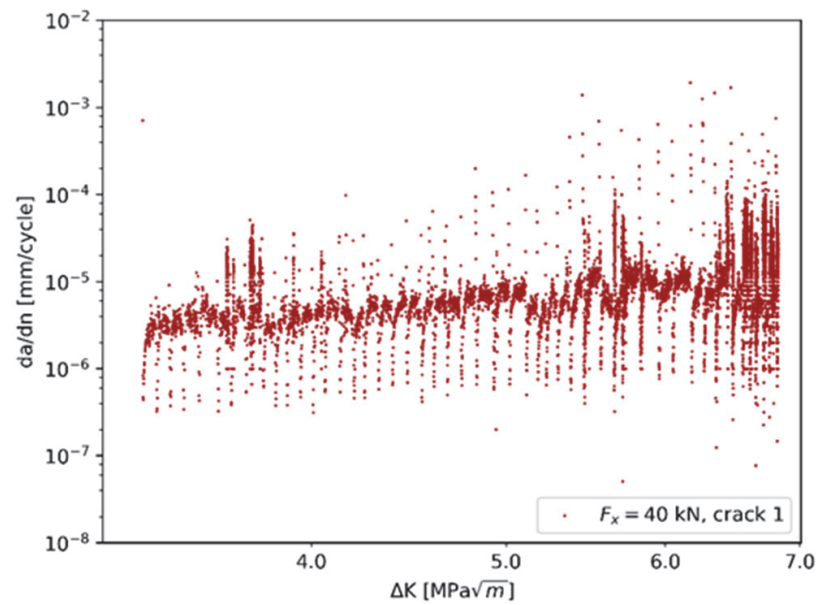

b)

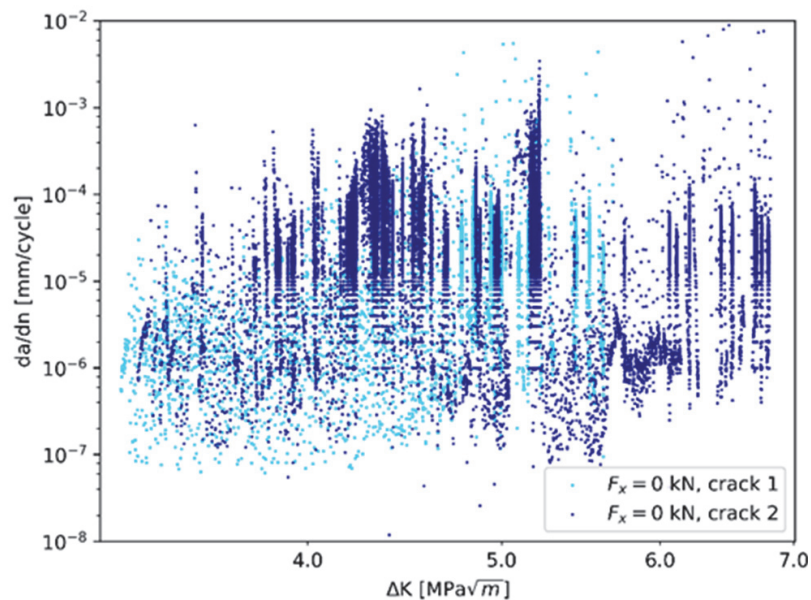

Figure 5: Crack growth rates vs. cyclic stress intensity factor range $\Delta K$, (a) for the sample with tensile loading in crack propagation direction $\left(F_{x}=40 \mathrm{kN}\right)$ and (b) without tensile load, i.e. $F_{x}=0 \mathrm{kN}$.

a)

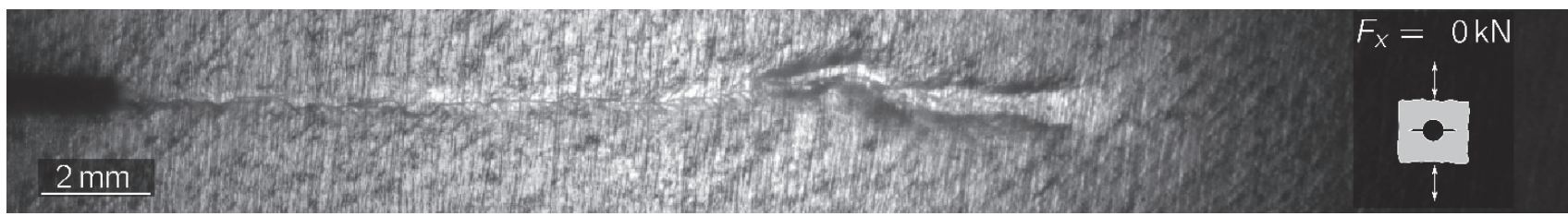

b)

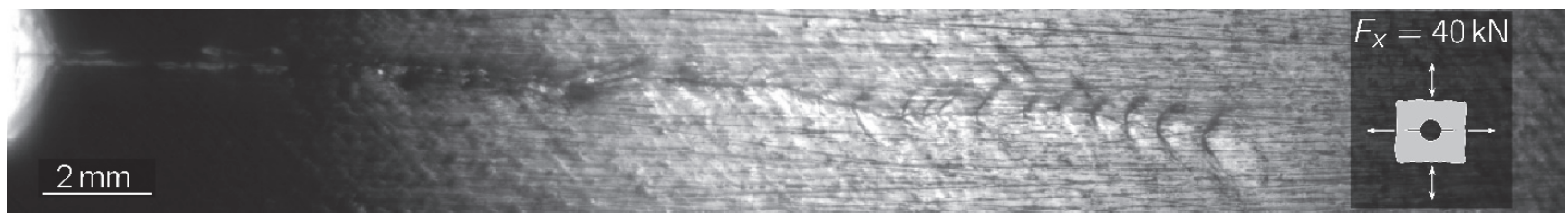

Figure 6: Comparison of the surface pictures of crack 1 at end of the tests with different superposed static loads in crack direction: (a) $F_{x}=0 \mathrm{kN}$ (negative T-stress), small spacing between the plastic zones resulting from the overloads, (b) $F_{x}=40 \mathrm{kN}$ (positive T-stress), larger spacing between the plastic zones resulting from the overloads 
a)

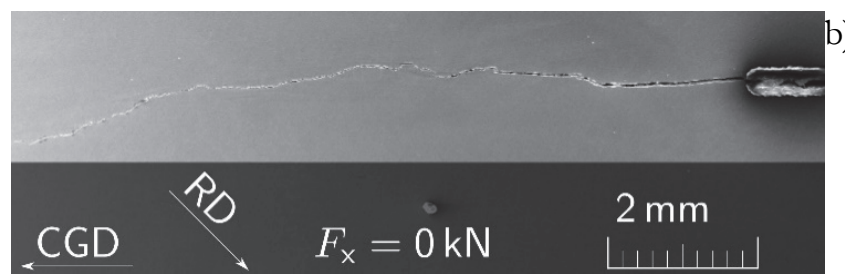

c)

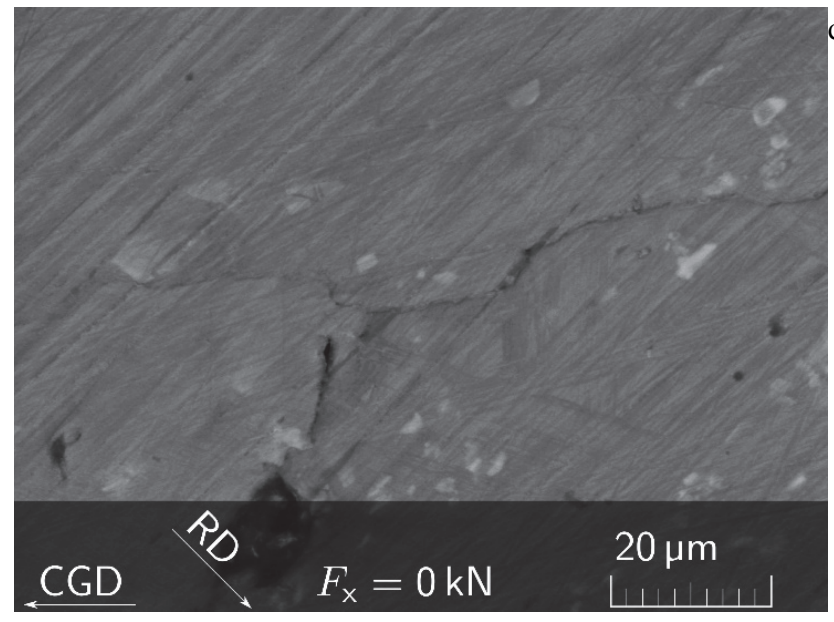

e)

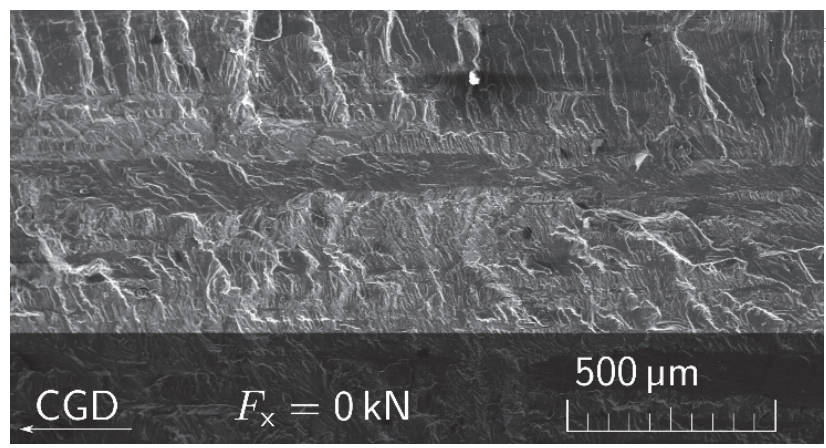

g)

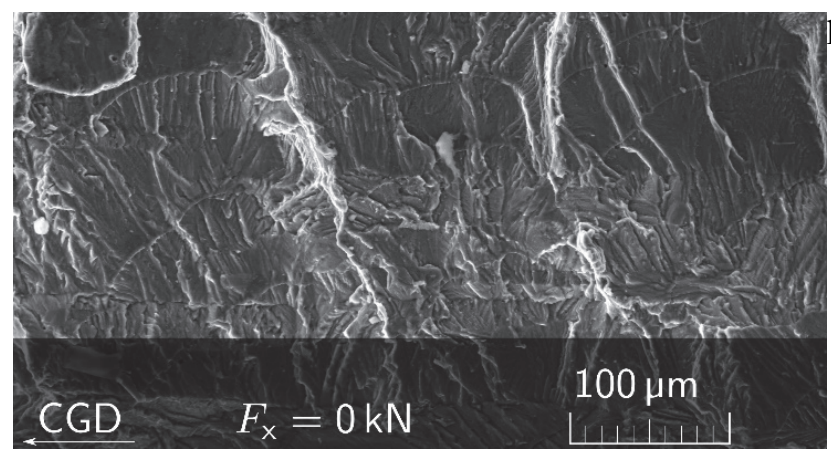

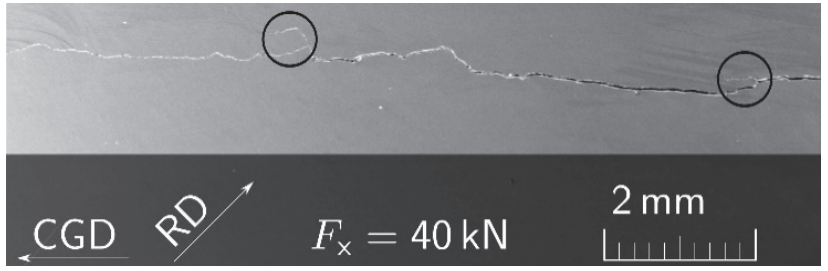

d)
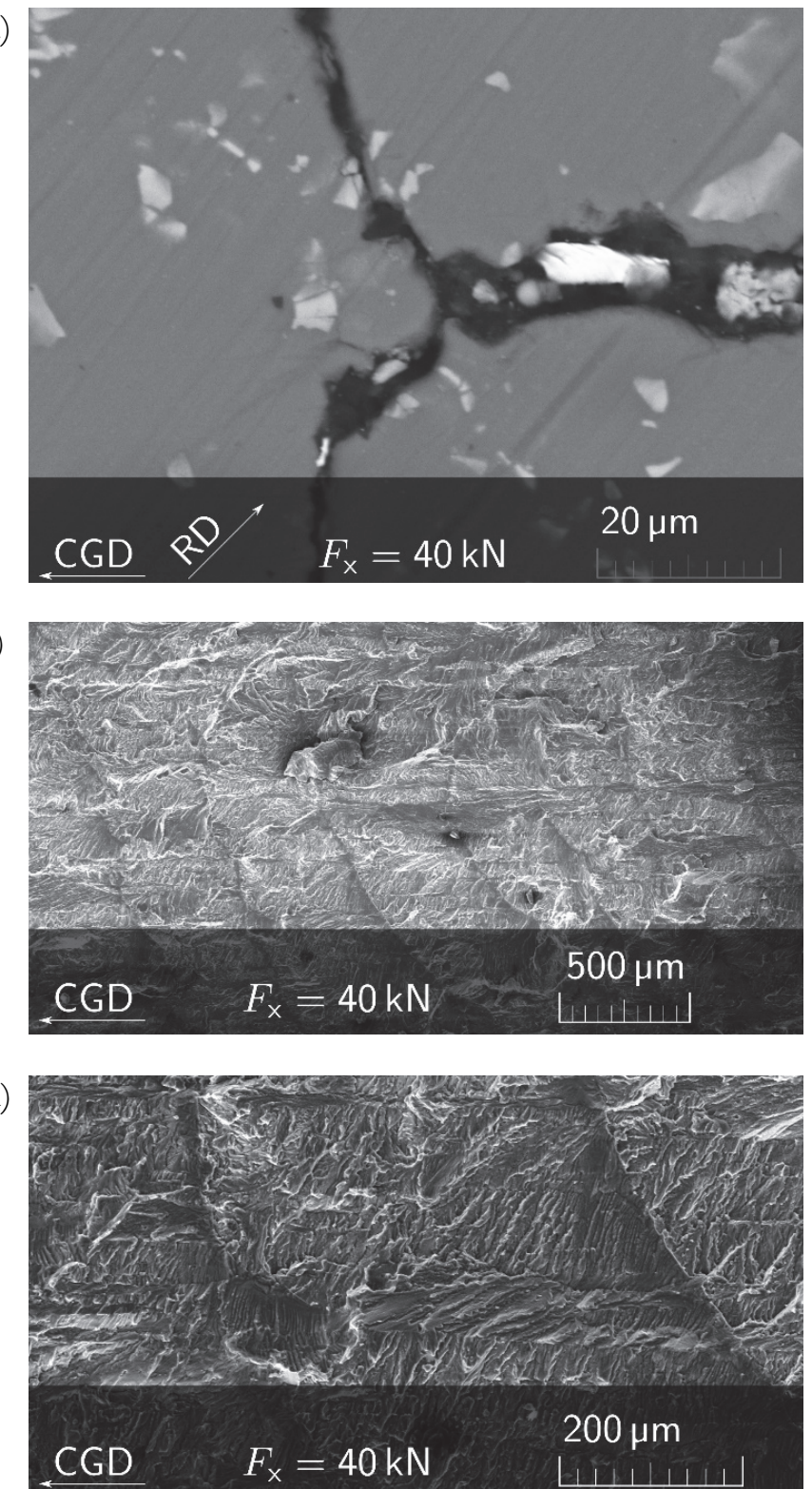

Figure 7: SEM micrographs of (a-d) specimen surfaces and (e-h) crack surface comparing tests with different superposed static loads in crack direction: (a, c, e, g) $F_{x}=0 \mathrm{kN}$ (negative T-stress) and (b, d, f, h) $F_{x}=40 \mathrm{kN}$ (positive T-stress) with rolling direction (RD) and crack growth direction (CGD). Crack branching occurs at the overloads viewable in pictures (b-d). Spacing between the overloads (every 100.000 cycles) in crack length are higher for $F_{x}=40 \mathrm{kN}$. Comparable micrographs at equal crack tip load $\Delta K$ (Crack length) are (e) and (f) as well as (g) and (h).

The two cracks grow asymmetrically. Crack 1 reaches the final crack length of $25 \mathrm{~mm}$ approximately 4 times slower than for the case $F_{x}=40 \mathrm{kN}$, crack 2 is approximately 6.5 times slower. The crack growth rate plotted in Fig. $4 \mathrm{~b}$ shows a lot of scatter. Acceleration directly after the overload can be found. Mainly, the crack growth rate is lower than at $F_{x}=40 \mathrm{kN}$. The 
reason for the less pronounced crack growth retardation in the case of $F_{x}=40 \mathrm{kN}$ is supposed to be the higher triaxiality and therefore reduced plasticity at the crack tip. Previous work by the authors with different biaxial ratios on the same sample has already suggested this effect [12].

A comparison of surface images of the two samples of crack number 1 can be seen in Fig. 6. Both images show the enlarged plastic zones at overload, which are larger in Fig. 6a than in Fig. 6b. With additional crack parallel loading (Fig. 6b), the crack grows faster between the overloads. Comparative scanning electron microscope images of the cracks are shown in Fig. 7. While for $F_{x}=0 \mathrm{kN}$ (Fig. 7a) no crack branching is visible at low magnification, for $F_{x}=40 \mathrm{kN}$ some large branching can already be detected (Fig. 7b). Under higher magnification (Figs. 7c and d), crack branches were found at almost every overload. It is known from the literature $[13,14]$ that crack branching can occur with overloads and influences the crack driving force, since mode II and mode III components also occur. The resulting branched crack path leads to increased crack closure. In order to minimize the effects of crack closure, this paper examines high static preloads $(\mathrm{R}=0.7)$.

\section{SUMMARY AND CONCLUSIONS}

$\mathrm{N}$ umerical calculations of a cruciform sample show that there is a good decoupling between the two loading axes. The solutions for the stress intensity factors of the specimen are given for symmetrically straight propagating cracks in the center of the specimen with $0^{\circ}$ and $45^{\circ}$ orientation to the loading directions. In the $0^{\circ}$ case only mode I occurs. The load along the second axis changes the constraint of the specimen. The T-stress solution is negative without a force $F_{x}$ and can be shifted to positive values by tensile loads in $F_{x}$. For the $45^{\circ}$ case the T-stress is low. Depending on the load ratio, mixed mode situations between $K_{\mathrm{I}}$ and $K_{\mathrm{II}}$ can be adjusted. Experiments with $0^{\circ}$ oriented cracks and overloads indicate that under tensile load in crack growth direction the retardation effect after a cyclic overload is less pronounced than without load in crack direction, which is explained by the reduced plasticity at the crack tip. The experiments were done under high static preloading at $\mathrm{R}=0.7$ to reduce crack closure effects.

\section{ACKNOWLEDGEMENTS}

7 he authors thank the involved staff of the Collaborative Research Center SFB 799 and acknowledge gratefully funding of Collaborative Research Center SFB 799, subprojects B4 and C5, by German Research Foundation (DFG). The authors thank AMAG rolling GmbH, Austria for supporting the aluminum material.

\section{REFERENCES}

[1] Hannon, A., Tiernan, P. (2008). A review of planar biaxial tensile test systems for sheet metal, Journal of Materials Processing Technology, 198(1-3), pp. 1-13, DOI: 10.1016/j.jmatprotec.2007.10.015.

[2] Dhondt, G., Kontermann, C. (2018). Combined LCF-HCF multi-axial crack propagation in cruciform specimens, 50. Tagung des DVM-Arbeitskreises Bruchmechanik und Bauteilsicherheit, Bruchmechanische Werkstoff und Bauteilbewertung, Paderborn, pp. 197-206.

[3] Mönch, E., Galster, D. (1963). A method for producing a defined uniform biaxial tensile stress field. British Journal of Applied Physics 14, pp. 810-812.

[4] Brown, M. W. and Miller, K. J. (1985). Mode I Fatigue Crack Growth Under Biaxial Stress at Room and Elevated Temperature. In Multiaxial fatigue, ASTM International, pp. 135-153. DOI: 10.1520/STP36221S.

[5] Dalle Donne, C., Trautmann, K.-H. and Amstutz, H. (2000). Cruciform specimens for in-plane biaxial fracture, deformation and fatigue testing. In: S. Kalluri and P.J. Bonacuse (Eds.) Multiaxial Fatigue and Deformation: Testing and Prediction. ASTM STP 1387. American Society for Testing and Materials, pp. 405-422. DOI: 10.1520/STP13517S.

[6] Matvienko, J.G. (2014). The effect of the non-singular T-stress components on crack tip plastic zone under mode I loading, Procedia Materials Science, 3, pp. 141-146, DOI: 10.1016/j.mspro.2014.06.026.

[7] Varfolomeev, I., Luke, M., Burdack, M. (2011). Effect of specimen geometry on fatigue crack growth rates for the railway axle material EA4T, Engineering Fracture Mechanics, 78, pp. 742-753,

DOI: 10.1016/j.engfracmech.2010.11.011. 
[8] Dittmann, F., Kaffenberger, M., Varfolomeev, I., Oechsner, M. (2017). Untersuchungen des Einflusses der Spannungsmehrachsigkeit auf die Rissfortschrittsrate, 49. Tagung des DVM-Arbeitskreises Bruchmechanik und Bauteilsicherheit, Bruchmechanische Werkstoff und Bauteilbewertung, Mittweida, pp. 199-206.

[9] Qian, C.-F. et al. (1996) Mixed-mode fatigue crack growth in stainless steels under biaxial loading. Journal of engineering materials and technology 118.3, pp. 349-355.

[10] Henkel, S., Holländer, D., Wünsche, M., Theilig, H., Hübner, P., Biermann, H., Mehringer, S. (2010). Crack observation methods, their application and simulation of curved fatigue crack growth, Engineering Fracture Mechanics, 77(11), pp. 2077-2090, DOI: 10.1016/j.engfracmech.2010.04.013.

[11] Henkel, S., Theilig, H., Hartmann, D., Hübner, P., Biermann, H. (2007). Numerical and experimental investigation of crack propagation paths in 6061 aluminium alloy under biaxial planar cyclic load, The eighth international conference on multiaxial fatigue \& fracture (ICMFF8Sheffield, GB, Conference-CD, S5B-1.

[12] Henkel, S., Liebelt, E., Biermann, H., Ackermann, S., Zybell, L. (2015). Crack growth behaviour of aluminum alloy 6061 T651 under uniaxial and biaxial planar testing conditions. Frattura ed Integrità Strutturale (Fracture and Structural Integrity), 34, pp. 466-475, DOI: 10.3221/IGF-ESIS.34.52.

[13] Borrego, L. P., Ferreira, J. M., Pinho da Cruz, J. M. and Costa, J. M. (2003). Evaluation of overload effects on fatigue crack growth and closure. Engineering Fracture Mechanics 70(11), pp. 1379-1397. DOI:10.1016/S0013-7944(02)00119-4.

[14] Sadananda, K., Vasudevan, A. K., Holtz, R. L. and Lee, E. U. (1999). Analysis of overload effects and related phenomena. International Journal of Fatigue 21, pp. 233-246, DOI: 10.1016/S0142-1123(99)00094-8. 